\title{
EL ARTE EN LOS MUSEOS MEMORIALES
}

\section{Art in Memorial Museums}

Pamela Sofía Dubois I pamela.sdubois@gmail.com

Facultad de Bellas Artes. Universidad Nacional de La Plata. Argentina

Directora: Marcela Andruchow marcela_andruchow@yahoo.com.ar Museología. Facultad de Bellas Artes. Universidad Nacional de La Plata. Argentina

Codirectora: Patricia Flier

pflier@hotmail.com Historia Social Argentina. Facultad de Humanidades y Ciencias de la Educación. Universidad Nacional de La Plata. Argentina

Recibido: 15/1/2019 Aceptado: 23/4/2019

\section{RESUMEN}

Esta investigación se propone analizar las representaciones de los acontecimientos generados por el terrorismo de Estado de la última Dictadura Militar (1976-1983). Toma como caso de estudio las representaciones en museos memoriales donde las prácticas artísticas activan las narrativas de la memoria social sobre el pasado reciente. Se considera que esas representaciones aportan a los reclamos contemporáneos de verdad, justicia y reparación, insertas en espacios que actúan como lugares de memoria consagrados al recuerdo de las víctimas, y a su transmisión intergeneracional. El caso específico a estudiar es el Museo de la Memoria de la ciudad de Rosario, provincia de Santa Fe.

\section{PALABRAS CLAVE}

Memoria; museo; arte

\begin{abstract}
This research intends to analyze the representations of the extreme events generated by State Terrorism of the last Military Dictatorship (1976-1983). It takes the representations in memorial museums where artistic practices activate the narratives of social memory about the recent past as a case study. It is considered that these representations contribute to the contemporary claims of truth, justice and reparation, inserted in spaces that act as places of memory dedicated to the memory of the victims, and to their intergenerational transmission. The specific case to be studied is the Museum of Memory of the city of Rosario, province of Santa Fe.
\end{abstract}

\section{KEYWORDS}

Memory; museum; art

1 El título completo del Plan de Tesis es La representación a través del arte como narrativa de la memoria social sobre el pasado reciente en el Museo de la Memoria de Rosario. Fue presentado en el año 2019 
Este trabajo intenta echar luz sobre la compleja y problemática relación existente entre los conceptos de memoria, museo y representación, conceptos tan amplios como disimiles en el mundo contemporáneo, que se constituyen como verdaderos campos de la praxis humana (Bourdieu, 1980). Una relación que atravesó varias décadas y que fue adquiriendo en su devenir diversas significaciones dependiendo de los contextos $y$, por ende, de las relaciones de poder que han dado lugar a intermitentes luchas y disputas que se expresan con mayor ímpetu en el sentido de transmisión de las memorias.

El objetivo principal de la investigación es analizar las diversas representaciones que se construyen a partir del lenguaje metafórico artístico en las complejas narrativas elaboradas por los museos memoriales para conmemorar y comunicar la memoria social sobre el pasado reciente.

Durante la década de 1970, varios países de América Latina sufrieron dictaduras militares que irrumpieron el orden constitucional y que hicieron uso de la fuerza pública del Estado contra los ciudadanos cometiendo crímenes mediante un sistema organizado. En este contexto, el 24 de marzo de 1976 en la Argentina se produjo el golpe de Estado que perduró hasta diciembre de 1983. Miles de personas fueron desaparecidas, torturadas y asesinadas, de las cuales aún hoy se desconoce su paradero. Esta era una de las tareas principales de los perpetradores: borrar toda huella, todo rastro que permitiese reconstruir esa historia, lo que se constituye como una de las principales deudas que tenemos no solo con el pasado, sino, también, con el presente y con el futuro. A partir de entonces, en la Argentina se proponen numerosas iniciativas e intentos de construir una memoria pública compartida, labor en la que se enmarca el Museo de la Memoria de Rosario. Desde allí se avanza significativamente en la identificación y en la recuperación de sitios donde ocurrieron acontecimientos y prácticas represivas del pasado reciente —campos de detención, lugares donde ocurrieron matanzas, edificios donde actores sociopolíticos del pasado fueron reprimidos- (Jelin \& Langland, 2003), como así también fueron recuperados y construidos otros espacios que, si bien no funcionaron como centros clandestinos de detención, materializan la represión (Scocco, 2016, p. 141), todas acciones que han dado lugar a numerosos debates, reflexiones, y luchas activas sobre el pasado.

Enmarcado, entonces, en estos intentos por cristalizar, ponerle forma y anclar la memoria en dispositivos para no olvidar, el Museo de la Memoria de Rosario, como lugar consagrado al recuerdo, promueve el acceso al conocimiento y a la investigación de las situaciones pretéritas de los derechos humanos y la memoria, en relación con el accionar del 
terrorismo de Estado, desde su patrimonio artístico conformado en su totalidad por obras de arte contemporáneo. Desde una perspectiva cualitativa, hemos previsto realizar un trabajo de campo en el espacio cultural seleccionado que habilite a interpretar el papel otorgado a las artes en todas sus dimensiones - sociopolítica, cultural, histórica y representacional- en el proceso de reconstrucción del pasado reciente, para conformar una narrativa museográfica que sostiene la misión del museo.

¿Pero cómo representar el horror? ¿Existe un lenguaje más apropiado que otro? El arte, como practica social, ¿logra reconstruir la memoria desde la esfera de lo simbólico?

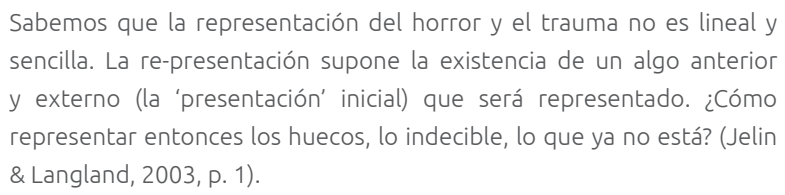

En este sentido es que el proyecto problematiza sobre las complejidades inherentes al proceso de construcción de una narrativa sobre la memoria desde el campo artístico y, más específicamente, desde las prácticas artísticas sustentadas por el Museo de la Memoria de Rosario, el cual se constituye como uno de los primeros museos en la Argentina que representa, a través de obras artísticas, el dolor generado por la lesión social de un pasado que no pasa, en un esfuerzo continuo por promover la construcción de ciudadanos activos, conocedores y responsables, capaces de defender sus derechos, de decir Nunca Más.

\section{REFERENCIAS}

Bourdieu, P. (1980). Questions de sociologie [Cuestiones de sociología] (Trad. Mabel Piccini). Francia, París: Minuit.

Jelin, E. y Langland, V. (2003). Monumentos, memoriales y marcas territoriales. Madrid, España: Siglo Veintiuno.

Scocco, M. (2016). La conmemoración de pasados traumáticos en Argentina. Sitios de Memoria y Museos en Rosario. Estudios Sociales Contemporáneos, (14), 140-154. Recuperado de https://ri.conicet.gov. ar/handle/11336/61132 